\title{
LOS INTELECTUALES NEGROS DE AMÉRICA: LA PERSPECTIVA CULTURAL COMO BASE DE LA CONSTRUCCIÓN DE UNA SUBJ ETIVIDAD DE CARÁCTER LIBERADOR (1920-1940)
}

Pedro Alexander Cubas-Hernández

\begin{abstract}
RESUMEN
En este ensayo serán analizadas cuatro experiencias intelectuales basadas en la cultura, que tenían el objetivo de generar autoestima en la población negra de América. El ideal panafricano de Marcus Garvey, la poesía del movimiento Negro Renaissance de Harlem, los versos renovadores de Nicolás Guillén y el periodismo incisivo de Gustavo Urrutia coadyuvaron a construir una subjetividad negra de carácter liberador.
\end{abstract}

PALABRAS CLAVE: intelectuales negros, movimientos culturales, siglo XX.

[...] no puede considerarse perfectamente instruído el ciudadano de un país negroide que sólo conoce la rama blanca de su pueblo $[\ldots]$

Gustavo E. Urrutia, $1935 .^{1}$

n los albores del siglo XX, África seguía siendo un continente desconocido desde el punto de vista cultural. Los viajes de exploración científica de especialistas europeos -que antecedieron el reparto territorial del Continente durante el último cuarto del siglo XIX- solo dieron el testimonio que los colonialistas necesitaban conocer para dominarlo y explotar

URRUTIA, Gustavo E. “Armonías: Aclaración”. Diario de la Marina, 1ra sección: 2, La Habana, 27 de diciembre de 1935. 
sus riquezas. Después, las artes plásticas, la música y la literatura hicieron más que la ciencia antropológica y el expansionismo imperialista rapaz: incluir el patrimonio cultural africano en el mapa estético universal. Así -a la luz de las vanguardias artísticas- se fue poniendo de moda el arte y la cultura negra durante la postguerra.

En esta época se observa un mayor acercamiento de carácter cultural, basado en lo estético, lo artístico, lo ético y lo religioso a (las representaciones de) África desde varias expresiones socio-culturales y políticas producidas en la diáspora de América. Por ejemplo, el ideal panafricanista incrementó su proyección internacional en los años 20 con las propuestas de William Du Bois y Marcus Garvey materializadas en congresos que programaron en sus agendas de debate algunos temas clave sobre África y sus descendientes en América. Otros movimientos culturales como el Harlem Renaissance de Nueva York y la experiencia etno-musicológica y literaria de Cuba fueron tan importantes como el negrismo de Haití y la negritud promovida más tarde desde París por intelectuales caribeños y africanos francófonos (estos dos últimos movimientos de matiz africanista no serán analizados en este ensayo).

El objetivo de este texto es reflexionar acerca de cómo la cuestión cultural tuvo un peso relevante en la producción de conocimientos para el debate entre los intelectuales negros de América en torno a cómo construir sus propias subjetividades para generar una autoestima liberadora ante los discursos y los relatos sustentados por las sociedades excluyentes en que vivían.

La propuesta panafricanista de Marcus Garvey tuvo éxito en un sector de la población negra de Nueva York. Sin embargo, Garvey no tuvo el mismo impacto entre los negros cubanos de clase media que residían en La Habana.

\section{I - El panafricanismo garveyista: retorno al edén africano.}

En 1921, durante la época de la crisis de postguerra el jamaiquino Marcus Mosiah Garvey (1887-1940) visitó Cuba. En aquel momento, en el contexto de Centroamérica y el Caribe, Cuba era uno de los países con mayor número de dependencias de la Asociación Universal para el Mejoramiento del Negro (UNIA, siglas en inglés: Universal Negro Improvement Asociation). ${ }^{2}$ Sus

2 Dicha organización había sido fundada en Jamaica, en 1914. 
afiliados en Cuba eran -en su mayor parte- jamaiquinos que se consideraban seguidores de los ideales garveyistas. En La Habana, Santa Clara, Camagüey y Oriente -lugares donde moraban inmigrantes antillanos anglófonos- fueron fundadas varias divisiones. ${ }^{3}$

La prensa habanera de la época -específicamente, el Heraldo de Cuba- se ocupó de la estancia de Garvey resaltando su discurso del 1 de marzo de 1921 en el Parque Santos y Artigas donde se reunieron alrededor de 500 negros de origen jamaiquino, estadounidense y británico. Además de elogiar la elocuencia de su retórica dicho diario señaló las ideas esenciales proferidas por el ilustre visitante: “... la completa liberación de la raza negra en todo el mundo y la constitución de un poderoso estado negro en el África." ${ }^{3}$ En el primer aspecto citado se resumía un objetivo de la UNIA como organización internacional (el fomento de la paz entre todos los hombres); ${ }^{5}$ y el segundo reflejaba otras dos metas relevantes (la constitución de una nación negra vigorosa e independiente en África; y la concreción del derecho de los negros a explotar las riquezas de dicho continente). Tales postulados revelan que Garvey fue un luchador anticolonialista radical -en el marco del pensamiento panafricanista- porque su proyecto iba dirigido a la total autodeterminación de su pueblo negro. Allí estribaba el fundamento del Back to Liberia (o to Africa), que venía promoviendo desde 1919 a través de la vertebración de flotas negras: primero con la Black Star Line of Steamers; y después en 1924 a través de la Black Cross Navegation and Trading Co. No obstante, ambas compañías fracasaron por no ser competitivas dentro de un mercado muy exigente. Además, el diario Heraldo de Cuba expuso los tres objetivos básicos del programa garveyista de acción, que fueron:

- La independencia económica.

- El mejoramiento social.

- El reconocimiento de la personalidad política para la raza negra. ${ }^{6}$

3 ESTÉVEZ, Sandra Rivero. La sombra de Marcus Garvey sobre el oriente cubano. Santiago de Cuba: Ediciones Santiago, 2005. p. 28. LEWIS, Rupert Marcus Garvey. Paladín anticolonialista. Ciudad de La Habana: Casa de las Américas, 1988.

4 "Próceres. Garvey: líder de los derechos de los negros". CD-ROM 100 Famosos en La Habana.

5 Este también fue un objetivo inicial de corte nacional de la UNIA desde su fundación: Promover una confraternidad universal y fortalecer los lazos de la hermandad y la unidad entre las razas. LEWIS, Rupert. Op. cit. p. 37.

6 ROSS, Yazmín. La flota negra. La Habana: Editorial Arte y Literatura, 2004, p. 187-197. 
Al revisar las perspectivas iniciales de la UNIA y compararlas con los tres tópicos citados se puede apreciar que no hubo cambios sustanciales en el quehacer garveyista entre 1914 y 1921 , pese a que la coyuntura internacional sí sufrió variaciones importantes. En los dos primeros puntos está presente la influencia del magisterio de Booker T. Washington, cuya biografía Garvey leyó con deleite. En este caso decir independencia económica y mejoramiento social implicaba sostener objetivos nacionales relativos a fomentar un mayor sentido del comercio y la industria, lo cual tomó espíritu de cuerpo en la $\mathrm{Ne}$ gro Factories Companies (una suerte de cooperativa de propietarios negros que controlaban restaurantes, imprentas, lavanderías y tiendas de ropa). ${ }^{7} \mathrm{Y}$ también significaba establecer institutos educativos e industriales para mejorar la educación y la cultura de mujeres y varones. Otra proposición que él tomó de Washington fue la de la necesidad de asistir y ayudar a los de menores recursos (una de las formas de hacerlo era a través de The Black Cross Nurses).

Cuando se hace referencia al controvertido tema en torno a la personalidad política de la raza negra (por el cual Garvey tenía tal vez ciertos puntos de contacto con William Du Bois), el jamaiquino consideraba que esa era una manera de vindicar a la denominada raza caída y, al unísono, promover su espíritu, el orgullo y el amor por ser negro. ${ }^{8} \mathrm{Al}$ conceder posteriormente una entrevista al Heraldo de Cuba, el apodado "Moisés de la raza negra» apuntó como motivos de su viaje de trabajo el hacer visitas a las sucursales de la UNIA en Morón, Nuevitas y Santiago de Cuba con el objetivo de conseguir apoyo de sus afiliados para su proyecto panafricanista. ${ }^{9}$

Garvey fue recibido por Mario García Menocal, Presidente de la República (en ejercicio de sus funciones hasta el 20 de mayo de 1921) porque lo consideraba un embajador de su raza. Además, en La Habana fue agasajado en el Club Lincoln, en la Unión Fraternal y en el Club Atenas. Sin embargo,

LEWIS, Rupert. Op. cit. p. 47-48. ESTEVEZ, Sandra Rivero. Op. cit. p. 48-52. Estudios y Compilaciones. La Habana: Centro de Estudios de África y Medio Oriente, 1984, v. 1, n. 1. p. 180; 190-191 (Mimeo).

7 Estudios y Compilaciones, op. cit. p. 192-193.

8 LEWIS, Rupert. Op. cit. p. 37.

9 FERNÁNDEZ-ROBAINA, Tomás. "Marcus Garvey desde la visión de Gustavo E. Urrutia". Identidad Afrocubana, cultura y nacionalidad. Santiago de Cuba: Editorial Oriente, 2009. p. 61. 
pese a tales muestras de respeto y cordialidad, la elite de la población negra autóctona (por ejemplo, los miembros del Club Atenas) discrepaba de sus puntos de vista ya que ellos se consideraban primeramente cubanos y luego negros. Además, le expresaron que no se sentían tan discriminados como los afro-norteamericanos ${ }^{10}$. En este punto Garvey difería porque él había comprobado en sus viajes por América y Europa que el negro era discriminado en todas partes del mundo. ${ }^{11}$ Lo cierto es que, a posteriori, la influencia garveyista en Cuba (y también en Estados Unidos) se fue disipando con el paso del tiempo, aunque en la región oriental cubana estuvo latente hasta $1935 .{ }^{12}$ La población jamaiquina se identificó con el discurso de Garvey debido a la realidad que este grupo vivía en Cuba, sufriendo el rechazo de la clase obrera cubana integrada por blancos y negros debido al papel que desempeñaban como rompehuelgas. ${ }^{13}$ Con su visita, Garvey tendió un puente entre Cuba y una de las versiones del Panafricanismo, amén de mostrar el vínculo de la comunidad negra nacional (incluyendo los inmigrantes anglófonos) con este intelectual, dirigente e ideólogo caribeño.

De regreso a Estados Unidos, Garvey continuó con su labor proselitista. De esa manera siguió demostrando una notable capacidad de convocatoria, que anteriormente había coadyuvado a la inauguración de una filial de la UNIA en Harlem, Nueva York. Allí comenzó la edición del periódico Negro World (1918-1933), que reflejaba los puntos de vista de dicha organización. Gracias al alcance mundial de su propaganda pudo efectuar cinco eventos internacionales en aquella gran ciudad. Los ocho congresos de la UNIA dieron fe de la labor de Garvey. En el primero (1920) lo más relevante fue la presentación de su "Declaración de los derechos de los pueblos negros del mundo" que interpelaba frontalmente al blancocentrismo. En ese pliego protestaba contra la opresión y discriminación racial; reclamaba la igualdad jurídica y

10 Todos los atributos relativos a la identidad afro aparecen separados por guión a pedido del autor del artículo, que entiende que esta es la forma más apropiada de expresión de esas identidades diferenciadas y en construcción. (N. E.)

11 FERNÁNDEZ-ROBAINA, Tomás, Op. cit. p. 62-63. ESTÉVEZ, Sandra Rivero, Op. cit. p. 48.

12 Solo la División de Banes (fundada en 1922) llegó hasta los años sesenta. Consúltese: ESTÉVEZ, Sandra Rivero, Op. cit. p. 58-66.

13 FERNÁNDEZ-ROBAINA, Tomás, Op. cit. p. 64. En las páginas siguientes el autor analiza las críticas de Gustavo Urrutia a los postulados ideológicos de Garvey. 
política; exigía el respeto a la dignidad negra; y abogaba por la independencia africana. Precisamente, en el siguiente cónclave (1921) se pronunció por la emancipación de Egipto, India (por la admiración que sentía hacia Ghandi)e, incluso, en apoyo de la lucha en pro de la autodeterminación de Irlanda (todas estas, colonias inglesas). ${ }^{14}$ Esos planteamientos anticolonialistas lo alejaron de Washington, su primer mentor espiritual; pero nunca lo acercaron a Du Bois que no compartía ni entendía la profundidad y el alcance del ideal garveyista. A todos los líderes de la comunidad negra norteamericana Garvey les ganó el pulso durante la primera mitad de los 20 gracias a su facilidad para movilizar a sus hermanos negros.

Mientras la UNIA de Garvey se "adueñaba" de Nueva York, Du Bois organizó los tres primeros congresos panafricanos en Europa (1919, 1921, 1923). En 1927 pudo efectuar en dicha ciudad norteña el IV Congreso Panafricano, en el cual fue condenada la intervención yankee en Haití y el problema de segregación racial en Sudáfrica; apoyó las independencias de Egipto, India y China, además del pedir el cese de la interferencia del gobierno estadounidense en los asuntos internos de los países centroamericanos y caribeños.

La acción garveyista que - pese a no abogar por la violencia, no descartaba la inclusión de organizaciones paramilitares como la African Legion - fue tildada de muy peligrosa en Estados Unidos. El escándalo financiero de la compañía naviera Black Star, por el cual Garvey sufrió prisión en 1923, confirmó la peligrosidad de la organización garveyista para los intereses de sus opositores y detractores. Después, Garvey fue procesado por las leyes federales en circunstancias en las que el verdadero objetivo era desacreditarlo políticamente (1927). $\mathrm{Y}$ en este contexto también pesaron de alguna manera sus discrepancias con líderes afro-norteamericanos de otras organizaciones. Finalmente, él fue expulsado del país y se llevó consigo su proyecto a Jamaica, donde intentó fortalecer una UNIA venida a menos tras una conturbada experiencia norteña.

De Garvey es justo destacar el significado de su "Declaración de los derechos de los pueblos negros del mundo" pues operaba como una contrapartida de la "Declaración de los derechos del Hombre y del Ciudadano"

14 Estudios y Compilaciones, p. 178-179. En Nueva York fueron organizados otros tres eventos de la UNIA en 1922, 1924 y 1926; después se efectuaron dos en Kingston, Jamaica, en 1929 y 1934. Y el último se celebró en Toronto, Canadá (1938). 
-acuñada por la Revolución Francesa de 1789- que tanto en la era moderna como en la contemporánea había servido para expoliar a los sujetos racializados (negros) y empobrecidos. Decir «Hombre» y «Ciudadano» era alimentar el individualismo del sujeto burgués porque solo quienes estaban al nivel de este sujeto podían ser denominados y reconocidos como tales. Pero el sujeto colectivo "pueblos negros del mundo", concebido por Garvey, tiene una proyección anticolonialista en busca de una autodeterminación definitiva en la que no hubiese espacio para la discriminación por el color de la piel. Su afán de reunirlos a "todos" en Liberia significaba no solo darle crédito al Back to Africa geográfico sino reconocer las potencialidades de un Continente muy rico en recursos culturales, naturales y minerales. Por eso siempre exigió que los negros pudiesen explotar directamente las riquezas africanas.

Además, Garvey veía una Europa desmoronada por la guerra y cada día creía menos en lo que consideraba falacias del viejo continente. En ese panorama, África era sinónimo de futuro para su pueblo negro porque, en este sentido, ¿a quién le importaba la derrota de Alemania? Si, en definitiva, sus posesiones africanas habían sido repartidas entre ingleses y franceses. Esta guerra de rapiña "entre blancos" (como él decía) le ayudó a comprender la necesidad de la descolonización; pero mientras esperaba por su consecución, Liberia (país que surgió como resultado de una construcción estadounidense y que fue la cuna del retorno al edén africano desde el siglo XIX) sería el laboratorio para materializar su sueño panafricano, un sueño que acarició y no vio realizado debido a su deceso. Sin embargo, el Back to Africa garveyista no pasaba de ser una idealización que no daba una explicación acerca de la complejidad de ese Continente exacerbada por la gestión divisionista del colonialismo europeo.

Paralelamente a estas actividades, Garvey también participó en el movimiento cultural Negro Renaissance de Harlem, que estaba más preocupado por los problemas específicos de los negros en Estados Unidos.

\section{II - E1 Negro Renaissance de Harlem: sus expresiones líricas.}

Harlem Renaissance (1919-1940) constituyó un movimiento social, cultural (arte, literatura y música) y político que enarbolaba el ideal del «Nuevo Negro» culto que daría su aporte inteligente a la sociedad. Además, influyó 
en el anticolonialismo, en la autodeterminación de los pueblos de África y tuvo un papel fundamental en el surgimiento del movimiento por los derechos civiles en Estados Unidos. De aquella generación intelectual participaron poetas tan importantes como Gwendolyn B. Bennett, Countee Cullen, Claude Mc Kay, Sterling Brown, y Langston Hughes; este último, uno de los que más ha trascendido. No obstante, otros poetas no menos importantes, como Carrie Williams Clifford y Lewis Alexander, también aportaron su sensibilidad y sapiencia.

Los poemas de Langston Hughes (1902-1967) muestran ante todo su identidad como sujeto racializado. Cuando escribió "Soy un Negro" expresó no solo su significado en el presente de Estados Unidos sino también el peso que esa condición social traía desde el pasado: "He sido esclavo.../He sido trabajador.../He sido una víctima..."15 Aun así, el sujeto lírico no se amedrentaba y exigía sus derechos diciéndoles a los White Anglo-Saxon Protestant (WASP) "Yo también canto a América":

[...]

Yo soy el hermano negro.

Me mandan a la cocina

cuando las visitas vienen;

\section{Mañana}

me sentarán a la mesa.

Y cuando las visitas lleguen,

ya nadie osará decirme:

"Vete a la cocina». ${ }^{16}$

He aquí una denuncia a la exclusión de los afro-norteamericanos de participar de las ventajas de la mesa común de la nación. Al decir "vete a la cocina” el poema también critica la invisibilización y, a la vez, destaca que su pueblo se prepara con optimismo para terminar con esa invisibilización desde la cocina riendo, comiendo y creciendo fuerte (léase empoderándose), para tomar su lugar en la mesa de donde nadie ya sería capaz de expulsarlos.

Hughes se autodefinía como negro y amaba a África; pero no podía desconocer la otra parte que tributaba a su identidad racial como "Mulato": "Yo

15 HUGHES, Langston. "Soy un negro”. PEREDA-VALDÉS, Ildefonso. Antología de la poesía negra americana. Santiago de Chile: Ediciones Ercilla, 1936. p. 34.

16 HUGHES, Langston. "Yo también canto a América". PEREDA-VALDÉS, Ildefonso. Op. cit. p. 35. 
soy su hijo, hombre blanco,/un pequeño bastardo amarillo." ${ }^{17}$ En consecuencia, su agonía resultaba aún mayor al definir dramáticamente su vida como una cruz que llevaba en su fenotipo "yellow" y que lo laceraba constantemente por sentirse como un indefinido racialmente, o sea, un "árbitro" entre las razas "claras" y "oscuras" que juegan el partido de su vida:

Un blanco fue mi padre, Si maldije a mi madre Madre murió en su choza y mi madre una negra. y le deseé el infierno, y padre en su palacio.

Si maldije a mi padre, que se encuentre en el cielo ¿¿Dónde moriré yo retiro mi blasfemia. ahora desearía. $\quad$ sin ser negro ni blanco ${ }^{18}$

Este ser o no ser -aunque no al estilo de "Hamlet" - es el resultado del colonialismo en América. Frente a este dilema, Hughes decidió reconciliarse simbólicamente con su madre mostrando su amor por África, que es la a(con) firmación de su negritud en la que, al igual que Garvey, aprendió a apreciar lo bello. Así, dice: “... verán que hermoso soy/ Y se arrepentirán... / [cuando me siente a la mesa común]/[de haber intentado excluirme, estigmatizarme e invisibilizarme]"19. Aquí se observa una posición de carácter estético de la cual también participaba Lewis Grandison Alexander (1900-1945) con su poema "El Hermano Negro", al aseverar: "Mirad, yo soy negro, pero también soy bello;/..."20

En ese mismo poema, Alexander reconoció su afinidad de criterios con las ideas que Hughes había expresado en poemas como "Soy un Negro" y "Yo también canto a América”. Pero no obviaba lo que significaba la aportación de los negros a la cultura y a la formación de una nacionalidad estadounidense que -en su opinión- estaba por encima de cualquier tipo de manifestación discriminatoria antinegra: "Yo soy el vástago de una raza de esclavos/ que ayudó a construir una nación poderosa para que tú y yo/ podamos soportar la mirada del mundo,/ audaces y firmes..."21

17 HUGHES, Langston. "Mulato”. PEREDA-VALDÉS, Ildefonso. Op. cit., p. 43.

18 HUGHES, Langston. "Cruz". PEREDA-VALDÉS, Ildefonso. Op. cit. p. 35-36.

19 HUGHES, Langston. "Yo también canto a América”. PEREDA-VALDÉS, Ildefonso. Op. cit. p. 35.

20 ALEXANDER, Lewis G. "El Hermano Negro”. PEREDA-VALDÉS, Ildefonso. Op. cit. p. 28.

21 Ibid. p. 28. 
Paralelamente, la identidad racial -amén de los juicios estéticos de autorreconocimiento- se complementa con una sensibilidad permeada de musicalidad y un sentimiento de alegría de vivir al cual los negros nunca renunciaron. Hughes apostilló: "He sido un cancionero:/ desde África hasta Georgia/ llevé mis canciones de tristeza, /inventé el «ragtime»."22 En este poema, Hughes abrazó las ideas de Du Bois, quien aseveraba que su pueblo negro tenía alma propia capaz de aportar cosas importantes a la Nación. Los cantos de aflicción fueron reconocidos por este último como el sustento de la voluntad del ser negro.

Otro elemento esencial de la lírica hughesiana es su enfrentamiento ante la estigmatización de su raza, que aprieta los puños y se queja de las injusticias en "Siempre lo mismo":

En todas partes lo mismo:

‥

Negro

explotado, golpeado, robado,

baleado y asesinado
[...]

En todas las tierras negras es lo mismo La que asesina, el poder que roba, el voraz que no se sacia $[\ldots]^{23}$

Este poema, además, revela la militancia política de Hughes, muy permeada por su admiración a la Revolución Socialista de Octubre que había triunfado en Rusia en 1917. Sus alusiones al «Ejército Rojo del Proletariado» y a la «Roja sangrienta bandera» que simbolizan «la vigorosa mano de la Revolución» indican que el sujeto sobre el cual reflexionaba Hughes debía ser revolucionario y luchar sin descanso en contra de la explotación imperialista, para después construir una sociedad más justa donde cesaría la discriminación racial. Para él, Moscú era la alternativa más idónea.

El jamaiquino Claude Mc Kay (1889-1948), por su parte, tuvo una larga experiencia de vida en la Rusia Soviética y aunque no se pronunció como un revolucionario radical como Hughes, también mostró en su pieza lírica "Si hemos de perecer" un gran espíritu de lucha:

22 HUGHES, Langston. "Soy un negro". PEREDA-VALDÉS, Ildefonso. Op. cit. p. 34.

23 HUGHES, Langston. "Siempre lo mismo". PEREDA-VALDÉS, Ildefonso. Op. cit. p. 39-40. 
Si hemos de perecer, que no sea como cerdos acosados por la jauría.

Perezcamos noblemente.

Que no se vierta nuestra sangre en vano.

Que hasta los mismos monstruos que combatimos

tengan que honrar nuestra muerte digna.

¿Qué importa el sepulcro abierto?

Afrontemos valientemente la jauría cobarde y asesina.

Derrotados, oprimidos, moribundos, pero combatientes. ${ }^{24}$

Este poema muestra el carácter indomable y tenaz de los pueblos negros de América. La historia de sus luchas enseña momentos de derrota y opresión que han segado la vida de muchos hermanos. Pero saber mantener una actitud combativa capaz de despertar la admiración del enemigo indica que no ha sido en vano ningún esfuerzo por liberarse del yugo a costa de sus vidas. Mc Kay reivindica la estirpe guerrera de los sujetos de su raza en la que no hay cabida para la cobardía y el deshonor.

Por su parte, Countee Cullen (1903-1946) examinaba las relaciones raciales en Estados Unidos donde había recrudecido el cisma social entre blancos y negros principalmente en el Sur. En este sentido, dibujó su "Cuadro" como un deseo de superación de la Línea del Color. En él proyectó una escena en la que se apreciaba como "Juntos, mano con mano, cruzan el camino/el muchacho blanco y el negro", desafiando a la sociedad que enarbola sus prejuicios en contra de la esencia humana: "Indiferentes a miradas y palabras,/ ellos pasan y miran sin sorprenderse/ de que brillando luminosamente como una espada/ el camino se enciende de truenos." 25

Precisamente, eso mismo estaban tratando de hacer los miembros (blancos y negros) de la National Association for the Advancement of Colored People (NAACP): un trabajo sostenido no solo a favor de mejorar las condiciones de vida de los negros sino también para lograr una armonía en las relaciones entre ambas razas en el contexto estadounidense.

${ }_{24}$ MC KAY, Claude. "Si hemos de perecer". PEREDA-VALDÉS, Ildefonso. Op. cit. p. 57.

25 CULLEN, Countee. "Cuadro”. PEREDA-VALDÉS, Ildefonso. Op. cit. p. 51. 
En los años 20 Harlem, un barrio neoyorkino de mayoría negra, era visto como la capital del mundo negro, al mismo tiempo que su ciudad nodriza, Nueva York, arrebataba a Paris el título honorífico de urbe non plus ultra universal. Esto tuvo su reflejo en la cultura. Por ejemplo, todos hablaban (sin echar de menos aquellos encantos del Moulin Rouge parisiense) de las divertidas noches del cabaré - solo para blancos-Cotton Club donde había bailarinas tan (y/o más) sensuales como (que) Josephine Baker, que tenía a Europa rendida a sus pies. En 1930 Richmond Barthé realizó y presentó al público esculturas, cuyas protagonistas eran las coristas de los night clubs de Harlem. Y en el campo literario Mc Kay compuso el poemario Harlem Shadows (1922) en el que destacan los versos de "La bailarina de Harlem", a través del cual describió la reacción del público masculino ante las fogosas expresiones corporales de una danzarina, cuya capacidad exorcista los hacía olvidar a las prostitutas que les acompañaban. ${ }^{26}$

Esta manera de admirar la sexualidad femenina -que propuso Mc Kayda cuenta no solo de la bohemia harlemita sino también de la defensa de un canon de belleza negro que enarboló Harlem. Gwendolyn B. Bennett (1902-1981) y Cullen escribieron sendos poemas con el mismo título: "A una muchacha morena". Ambos defendían la belleza corporal y sensual de la mujer negra así como su capacidad para despertar sentimientos amorosos en los hombres. «Reina» es la palabra que utilizaron para definir su devoción por las féminas que los inspiraron. Bennett subrayó con pasión: “Te amo porque eres morena/y por las redondeces oscuras de tus senos/ [...].” Y un Cullen más lascivo manifestó su hombría exhortando a sus semejantes: "[...]/Chaval, nunca contengas el ardor de tu cuerpo/en presencia de la belleza." 27

El poema de Bennett intentó un final optimista: “... /olvídate que alguna vez fuiste esclava/y deja que tus gruesos labios sonrían al destino." 28 Pero la mujer de quien habla no parece estar lista para enfrentar el futuro, puesto

26 MC KAY, Claude. “La bailarina de Harlem”. PEREDA-VALDÉS, Ildefonso. Op. cit. p. 56-57.

27 BENNETT, Gwendolyn B. "A una muchacha morena”. PEREDA-VALDÉS, Ildefonso. Op. cit. p. 46. Y CULLEN, Countee. "A una muchacha morena”. PEREDA-VALDÉS, Ildefonso. Op. cit. p. 50.

28 BENNETT, Gwendolyn B. "A una muchacha morena”. PEREDA-VALDÉS, Ildefonso. Op. cit. p. 46. 
que muestra una frágil tristeza en su voz en la que también solloza una esclava indolente. Y -como infortunio en valor agregado- ella nació para tristes nupcias. Por tanto, el poeta la exhorta a preservar el aparentemente único atributo que ella posee para salir adelante: “... / conserva lo que tienes de reina en tus maneras/..."29. Es decir, la expresión corporal de una elegancia ancestral. Sin embargo, Cullen reflexionaba a otro nivel existencial "Porque hay lugar para la felicidad/en el orgullo y la pureza de la carne de ébano,/..." ${ }^{30}$ En su opinión, las féminas negras reinaban hasta después de muertas, porque tras ser sepultadas las ánimas no les preguntan por su color de piel y las acogían en su galaxia.

Este tipo de poesía solo percibía a la mujer como un objeto del placer sexual e incapaz de hacer valer su inteligencia como sujeto social. Además, participaba de la visión machista de concebir una mujer digna de lástima, débil, infeliz y sumisa -tal cual la presentaba Bennett-, lo que implicaba seguir siendo tan (o más) esclava como (que) antes.

En otro ámbito pero en un registro muchas veces análogo, hubo en Cuba poetas como Nicolás Guillén que escribían versos exaltando la cotidianidad de los negros, sus formas de expresarse y comunicarse, así como la sensualidad de las mujeres y el poder seductor de los hombres.

\section{III - La lírica de Nicolás Guillén: ¿negrismo o mulatismo?}

Nicolás Guillén Batista (1902-1989) ha trascendido por su extensa obra poética en la que sobresalieron sus versos dedicados al componente negro de la población cubana. La musicalidad es un rasgo relevante en la lírica guilleniana. En los años veinte entraron con fuerza en los salones de la alta sociedad cubana ritmos populares como el jazz (norteamericano), la rumba y el son oriental (nativos) que compitieron con el declinante danzón-aclamado en las décadas anteriores como baile nacional (criterio este que aún persiste en Cuba) - y acabaron por desplazarlo. En tales géneros musicales novedosos estaba la herencia africana. Guillén lo sabía, y teniendo presente que el son montuno estaba boga, tituló su primer poemario Motivos de son (1930).

29 Ibid. p. 46.

30 CULLEN, Countee. "A una muchacha morena”. PEREDA-VALDÉS, Ildefonso. Op. cit. p. 50. 
Valiéndose de su lirismo, Guillén logró visibilizar a un sujeto negro empobrecido y que no contaba para la Cuban High Life. El lenguaje (léase, especialmente, la fonética) que utilizó era el que se escuchaba por las calles de La Habana a algunos negros de los denominados sectores marginales. Entre los primeros poemas, se encuentra una exhortación a un "Negro Bembón”, para que no se afligiese por no quedar encuadrado en los cánones de belleza eurocéntricos porque su raza también tiene su propio patrón estético, tan válido como el otro:

¿Po qué te pone tan brabo, cuando te disen negro bembón, si tiene la boca santa, negro bembón?
Bembón así como ere tiene de to; Caridá te mantiene, te lo da to. ${ }^{31}$

Al mismo tiempo, en "Mulata" Guillén se mofaba de las personas que por verse con la piel clara se creían más importantes y menos discriminados que quienes tienen una pigmentación oscura. Así, en tono burlón, irónico o sarcástico apuntó: "Y fíjate bien que tú [mulata]/ no ere tan adelantá,/ poqque tu boca e bien grande,/ y tu pasa, colorá" ${ }^{32}$

En estos versos también se nota la omnipresencia del machismo de la sociedad cubana puesto que el hombre se muestra autoritario ante la mujer cuando le habla o interpela; así como la referencia al trabajo arduo de mujeres que se esforzaban para mantenerles los gustos a sus hombres (esposos y/o amantes, hijos, sobrinos, nietos). También en los poemas "Mulata" y "Mi chiquita" se aprecia la concepción mítica del poder de la sensualidad de las mujeres negras por encima de las mulatas (tildadas sarcástica o irónicamente como el mejor invento del colonizador blanco), pues en esa discordia las blancas poco interesan:

Si tú supiera, mulata, la veddá, ¡que yo con mi negra tengo, y no te quiero pa na! ${ }^{33}$
La chiquita que yo tengo tan negra como e, no la cambio po ninguna, po ninguna otra mujé. ${ }^{34}$

31 GUILLÉN, Nicolás. Motivos de son. Cervantes Virtual: http://www.cervantesvirtual.com/ obra-visor/motivos-de-son-1930--0/pdf , 15/11/2006.

32 Ibid.

33 Ibid.

34 Ibid. 
Esto a la vez tiende a reforzar la fama de excelente amante del hombre negro, que gracias a su presunta capacidad de dar el máximo placer sexual a cualquier fémina, se creía con el derecho a ser consentido y a sentirse siempre deseado por ellas: "Ella me dise: mi santo,/ tú no me puede dejá;/ bucamé,/ bucamé,/ bucamé,/ pa gosá.”35

Detrás de este alarde de masculinidad se esconden los vagos y los proxenetas que viven del esfuerzo de las mujeres. Y pueden incluirse también otros aprovechadores de baja calaña. Así por ejemplo, el negro bembón del poema no deja a Caridá porque ella satisface sus caprichos (lo viste y lo calza); y lo mismo se nota en su congénere que no cambia a su negrita (que le cocina, le lava, le plancha y, además, le satisface sexualmente) por la primera que pase frente a él aunque sea mulata (¿Y si fuera blanca, qué sucedería?). Guillén exaltaba un tipo de sujeto marginalizado que no representaba el progreso por el cual luchaban los negros. No obstante, considero que él acertó en mostrarlos tal cual eran, pese a folclorizarlos en demasía. Por otra parte, Guillén retrató también con acierto a las mujeres que se burlaban de los hombres, quienes al percatarse del engaño solo atinaban a decir "Si tú supiera..."

¡Ay, negra,

si tú supiera!

Anoche te bi pasá

y no quise que me biera.
A é tú le hará como a mí, que cuando no tube plata te corrite de bachata, sin acoddadte de mí. $[\ldots]^{36}$

En 1930, Cuba estaba sufriendo los efectos de la crisis económica mundial iniciada a fines del año anterior. Guillén se hizo eco de esa situación en sus poemas de Motivos de son cuando decía en diferentes contextos "Hay que tené boluntá" y "Búcate plata": 
Empeña la plancha elétrica, pa podé sacá mi flú;

buca un reá,

buca un reá,

cómprate un paquete vela

poqque a la noche no hay lu.

¡Hay que tené boluntá,

que la salasión no e

pa toa la bida! ${ }^{37}$
Búcate plata,

búcate plata,

poqque no doy un paso má:

etoy a arró con galleta,

na ma.

Yo bien sé cómo etá to, pero biejo, hay que comé:

búcate plata, búcate plata,

poqque me hoy a corré. ${ }^{38}$

Estos dos fragmentos revelan la cotidianidad de los negros empobrecidos (vivida también por los blancos de igual rango social). Ese vivir al día tan paradigmático donde el factor dinero pesa tanto en la posibilidad de conseguir alimentación como en el aseguramiento de mínimas condiciones de vida. Pero lo cotidiano de Cuba no está completo sin la impronta del elemento anglosajón, cuya tarjeta de presentación principal es la lengua. Cuando el poeta le decía a su persojane Bito Manué "Tú no sabe inglé” porque “.../ tu inglé era de etrái guan,/ de etrái guan y guan tu tri./ [...]"39, como en el béisbol, parece que se mofaba de él ya que no era capaz de conseguir una novia norteamericana. Sin embargo, ese modo sutil de referirse a lo socialmente inalcanzable para los que tienen menos recursos no fue su única preocupación. El verdadero espíritu de estas líneas poéticas era fustigar a Estados Unidos, que no solo intervenía en la política y hacienda del país, sino que también hacía sentir la potencia de sus patrones culturales a todos los sectores de la población. La filiación política anti-yankee de Guillén comenzaba a visibilizarse mejor.

Si en Motivos de son se sienten los latidos de la música popular tradicional cubana, en Sóngoro cosongo (1931) esa sensación es mucho mayor porque la rumba occidental firmó un pacto con el son oriental. Pero uno de los aspectos más importantes del pensamiento de Guillén está inscrita, a modo de declaración jurada, en el "Prólogo" de este poemario: 
...una poesía criolla entre nosotros no lo será de un modo cabal con olvido del negro. El negro - a mi juicio - aporta esencias muy firmes a nuestro coctel. Y las dos razas que en la Isla salen a flor de agua, distantes en lo que se ve, se tienden un garfio submarino, como esos puentes hondos que unen en secreto dos continentes. Por lo pronto, el espíritu de Cuba es mestizo. Y del espíritu hacia la piel nos vendrá el color definitivo. Algún día se dirá: «color cubano». ${ }^{40}$

Darle crédito a la utopía "color cubano" es - a decir de Guillén- el total reconocimiento de que Cuba es una tierra mestiza (léase mulata) donde biológica $y$ culturalmente se fundieron lo africano y lo español (en general lo europeo también); es el lugar en el cual negros y blancos bailan y cantan el mismo son asi como los demás ritmos musicales; $y$, además, Changó y Santa Bárbara conviven sin disputar un espacio en la religiosidad popular sincrética. Asi sonaba a nivel social "La canción del bongó", a través de la cual Guillén habla: “-Aquí el que más fino sea,/ responde, si llamo yo./ Unos dicen: Ahora mismo,/ otros dicen: Allá voy." ${ }^{11}$

En lo que atañe a la música, en Sóngoro cosongo se aprecia la preponderancia de la rumba; aunque no se especifiquen sus modalidades (guaguancó, yambú y columbia) porque los poetas vanguardistas cubanos de los 20 y 30 no las definían explícitamente en sus composiciones. Aquí destaco "La canción del bongó", "Canto Negro", "Secuestro de la mujer de Antonio" y "Rumba". La conga entró en escena al compás del "Organillo" y se alió con la rumba en el "Velorio de Papá Montero" (zumba, canalla rumbero!). En aquella época, Rita Montaner e Ignacio Villa "Bola de Nieve" cantaron/musicalizaron, cada cual con su estilo y sabrosura, el poema "Quirino" (con su tres!). Además, lo cotidiano de las barriadas habaneras y de los pueblos de tierra adentro se hizo sentir con el ritmo musicalísimo del "Pregón", que tanto elogiaba Gustavo Urrutia en sus escritos de 1929 sobre economía (promoción de la pequeña empresa privada).

40 GUILLÉN, Nicolás. Sóngoro cosongo. Cervantes Virtual: http://www.cervantesvirtual.com/ obra-visor/songoro-cosongo-1931--0/pdf, 15/11/2006.

41 Ibid. 
En el poemario Sóngoro cosongo, los ídolos nacionales como el pugilista rentado y campeón mundial Eligio Sardiñas, «Kid Chocolate», tuvieron su tributo lírico en formato de una "Pequeña oda a un negro boxeador cubano”. Y el dramatismo de la explotación (“¡Sangre/ que se nos va!”) está en el corte de "Caña", donde reaparece el compromiso político antiimperialista guilleniano en plena Revolución de 1930, que marcó un hito histórico esencial en Cuba. ${ }^{42}$

Resultan interesantes en este segundo poemario, tan musical como el primero, las palabras de Guillén para una "Mujer nueva”, pues tienen un carácter diferente a las que había utilizado para describir a las negras en sus poemas de juventud (incluyendo Motivos de son):

Con el círculo ecuatorial

ceńido a la cintura como a un pequeńo mundo,

la negra, mujer nueva,

avanza en su ligera bata de serpiente.

bor. ${ }^{43}$

Coronada de palmas

como una diosa recién llegada,

ella trae la palabra inédita,

el anca fuerte,

la voz, el diente, la mañana y el salto.
Chorro de sangre joven

bajo un pedazo de piel fresca, y el pie incansable para la pista profunda del tam-

Estamos en presencia de una mujer negra joven que está lista para luchar a favor de un cambio social como una compañera dispuesta ante cualquier contingencia. Ella aparece represetnada como una Madre Cuba en sí misma (detalle visible pese a que el bardo se cuidó de develar el feminismo militante de su musa inspiradora), que exigía respeto y varios oídos sensibles para sus criterios de liberación material y espiritual. Por ejemplo, acceder al sufragio como garantía de una verdadera ciudadanía.

Por último, con el poemario West Indies, Ltd. (1934) Guillén volvió a referirse a la identidad racial que dignificaba al sujeto negro de Cuba; pero que 
también ha sido objeto de la injusticia. Mediante un juego de "Adivinanzas" reveló el profundo sufrimiento que arrastraban desde sus antepasados esclavizados y se posicionó al lado de ese sujeto colectivo invisibilizado, excluido y marginado que solo tenía como defensa su sonrisa, cual la mañana que ilumina la vida, para paliar el llanto de su cuerpo castigado por la mentira, la hipocresía y la desvergüenza del blanco colonialista:

En los dientes, la mañana,

y la noche en el pellejo.

¿Quién será, quién no será?

-El negro.
Un hombre que está llorando

con la risa que aprendió.

¿Quién será, quién no será?

-Yo [Nicolás Guillén Batista]. ${ }^{44}$

En dicho poemario, Guillén retomó las temáticas expresadas en sus textos anteriores. Por ejemplo, en "El abuelo", expuso el caso de una mujer rubia que ignoraba que por sus venas corría sangre negra ya que su antepasado no tenía su mismo color de piel. Con este mismo espíritu de (re)pensar el tema complejo de las identidades, el bardo escribió los poemas "Balada de los dos abuelos" y "Dos niños", que testimonian una concepción de mestizaje cultural que marca los discursos y relatos de la década del 30. Y, al mismo tiempo, continuaba su vocación musical afro-cubana en "Sensemayá", "Balada del Güije", "Balada de Simón Caraballo", "Caminando" y "Calor". Además, hay versos que responden a su filiación política comunista y marxista: "Maracas", "Guadalupe W. I.” y "West Indies, Ltd.”, que da título a la obra en la cual Guillén estaba perfilando un sujeto colectivo cada vez más comprometido con la necesidad de cambiar la realidad social de la nación cubana de los años 30, pese a promover un discurso mulatista que tenía poco de liberador para los sujetos negros cubanos.

Guillén estuvo vinculado al proyecto cultural «Ideales de una Raza»y poco a poco se fue convirtiendo en uno de los máximos colaboradores de Gustavo Urrutia, a quien le unió una grande amistad pese a las diferencias ideológicas entre ambos.

${ }^{44}$ GUILLÉN, Nicolás. West Indies Ltd. Cervantes virtual: http://www.cervantesvirtual.com/ obra-visor/west-indies-ltd-1934--1/html, 15/11/2006. 


\section{IV - Gustavo Urrutia en dos espacios mediáticos cubanos.}

En abril de 1928 el Diario de la Marina sorprendió a la opinión pública cubana al iniciar la circulación de una sección cuyo tema central era mostrar la actualidad del progreso cultural de los negros. Fue bautizada por la jefatura de la redacción central con el nombre ambiguo: «Ideales de una raza». De este espacio estuvo a cargo Gustavo Eleodoro Urrutia Quirós (1880-1958). Primero salió solamente en formato de columna semanal; y, por su éxito, el 11 de noviembre de 1928 fue insertada como página en el "Magazine dominical" del Diario.

En el marco de la reflexión para la construcción de sujetos trascendentes es preciso destacar dos series temáticas preparadas por Urrutia, que aparecieron en la columna semanal. Ambas tienen un carácter nacionalista: "La raza cubana" (1928) y "La cuestión económica del negro" (1929). También hubo otros artículos interesantes que explicaban la problemática de las relaciones raciales en Cuba a fines de los años veinte y principios de la década de 1930. En enero de 1931, «Ideales de una Raza» dejó de circular debido a razones internas del Diario de la Marina, cuya directiva decidió retirar el suplemento dominical. No obstante, en febrero de ese año, Urrutia volvió al trabajo a través de la columna "Armonías" que, con anterioridad, funcionaba como Editorial de la plana dominical de "Ideales...". Durante los 30 Urrutia -además de cumplir con sus funciones de columnista- produjo dos obras de suma importancia que marcaron su mayoría de edad como intelectual: "Cuatro charlas radiofónicas" (1935) y "Puntos de vista del Nuevo Negro” (1937), que no será analizado en este ensayo.

Las "Cuatro charlas radiofónicas" fueron realizadas en la estación radial CMCF-815 k. c. de La Habana los días 11, 14, 18 y 21 de diciembre de 1935. El programa se denominaba: «Hora Afro-Cubana» (título de la primera charla) y se transmitía los miércoles y sábados en horario estelar nocturno (8-9 pm). Urrutia lo definió como una hora de exégesis y reivindicación culturales de los negros cubanos, cuya misión era folclórica, investigadora y expositiva. Esta cuarteta de alocuciones radiales -que reprodujo a posteriori en la sección "Armonías"- marca un momento importante de Urrutia como pensador pues sintetizó los tópicos esenciales que venía discutiendo desde 1928 en torno a los sujetos negros de Cuba. 
En la primera charla analizó el significado internacional de la cultura africana después de la I Guerra Mundial, sobre todo en Europa Occidental donde fue admirada mas no valorada en profundidad, puesto que "lo negro" se concibió como espectáculo (cuyas prestaciones artísticas se veían como servicios cotizables) hasta convertirse en un modismo. Esto repercutió en Estados Unidos donde fue un espléndido filón de deleites mundanales (Harlem); Latinoamérica lo asumió acríticamente en formato de decreto esnobista; y en Cuba fue considerada inicialmente como un lamentable recrudecimiento y después se convirtió en un vicio.

Seguidamente, Urrutia criticó la industrialización, sofisticación y teatralización de "lo negro" ya que provocaba su degeneración, además de atribuirle a la cultura negra una decadencia que sufría Europa en aquella época. En este sentido, afirmaba que África era más que una moda europea (moda esta que, en la práctica, invisibilizaba el verdadero espíritu africano), al paso que objetivamente, por ejemplo, el reino de Abisinia (Etiopía) había sido invadido por la Italia fascista de Benito Mussolini (Urrutia hizo una sutil referencia a este hecho) en 1935. Por último, Urrutia fustigó la situación de «elegante servidumbre» en la cual estaban sumidos el negro y su arte haciendo reír, bailar y sentir al blanco que pagaba para ver un espectáculo. ${ }^{45}$

Las dos charlas siguientes "El Plus-Dolor" y "Complejo de inferioridad” guardan entre sí una estrecha relación. Urrutia profundizó el significado del concepto de «Plus dolor» que es clave en su pensamiento. A su modo de ver, el sujeto negro no solamente sufre por el color oscuro de su piel, sino que también se duele por tener sus aspiraciones reducidas a ser campesino, obrero, empleado público y profesional ya que los otros ámbitos sociales de mayor rango (la diplomacia por ejemplo) les estaban negados; la mujer negra se enfurece pues no la contratan como dependiente en tiendas lujosas y otros trabajos industriales donde admitían a chicas blancas; a los jóvenes "de color" les sucedía lo mismo; el concepto peyorativo del trabajo heredado del hidalguismo español, "esta labor es cosa de negros", seguía pesando; y, por último, influye el dolor de la comprensión de que los blancos no quieren percatarse de que la cubanidad seguirá vegetando mediatizada si la tercera parte de la

45 URRUTIA, Gustavo E. "Armonías: Hora Afro-Cubana”. Diario de la Marina, 1 ra sección: 2, La Habana, 18 de diciembre de 1935 
población permanece sumida en todas las miserias y en la subordinación. ${ }^{46}$

A partir del término «subordinación», Urrutia analizó lo concerniente al complejo de inferioridad. Él lo definió como la zalamería del negro "leído y escribido" que tiene alma esclava y espíritu pordiosero. Ese es la persona negra permeada de "picuísmo» ${ }^{47}$ porque reniega de sus ancestros africanos para elogiar la cultura eurocéntrica (que desde siempre le había hecho ver lo no europeo como inferior e intrascendente). Esto explica por qué muchos negros pedían perdón frecuentemente por su linaje africano para ser aceptados por los blancos a quienes no se cansaban de imitar. Urrutia logró comprender que este "picuísmo negro" basado en un complejo de inferioridad étnico-cultural constituía un achaque universal que había repercutido en Cuba. En su opinión, la esclavitud de ayer se recordaba como una fuente de rebeldía lo cual era motivo de orgullo, en tanto que la esclavitud contemporánea subsistía en el proletariado. Por eso se preguntaba: ¿A quién se le ocurre aquí y ahora negar su condición de proletario, de esclavo moderno, o abochornarse de ella? Al aclarar su posición ante esta tara de la mentalidad colonial subrayó que los negros deberían saber lo que realmente querían hacer a favor del progreso de Cuba y discutir sus puntos de vista con los blancos, pero nunca aceptar irreflexivamente los criterios impuestos por los blancos. ${ }^{48}$

En la cuarta charla, expresada a modo de "Aclaración", ${ }^{49}$ Urrutia manifestó la importancia de conocer y explicar el africanismo en todas sus vertientes culturales, específicamente, musicales y religiosas (rituales de ñañiguismo y santería). En esta última alocución, Urrutia retomaba lo dicho en la plática inaugural acerca de la riqueza que contienen los valores morales, artísticos y religiosos de África de los cuales son portadores el pueblo cubano en general y los negros en particular. Por esta razón, consideraba que el negro cubano no debería sentirse abochornado, denigrado y coaccionado por presuntas herencias de inferioridad que le

46 URRUTIA, Gustavo E. “Armonías: El Plus-Dolor”. Diario de la Marina, 1 ra sección: 2, La Habana, 21 de diciembre de 1935.

47 Picuísmo viene de la palabra popular «picú», que significa fatuo, pesado, falso, hipócrita, insoportable.

48 URRUTIA, Gustavo E. "Armonías: Complejo de inferioridad”. Diario de la Marina, 1ra sección: 2, La Habana, 22 de diciembre de 1935.

49 URRUTIA, Gustavo E. “Armonías: Aclaración”. Diario de la Marina, 1ra sección: 2, La Habana, 27 de diciembre de 1935. 
endilgaron los blancos ignorantes. En este sentido, le exigió a su pueblo negro la reivindicación de su propia estimación porque conociéndose mejor se autoestimarían y, de la misma manera, se harían estimar por sus conciudadanos blancos.

Las experiencias intelectuales abordadas en este ensayo estaban basadas en la fuerza de la cultura para generar autoestima en la población negra de América construyendo una subjetividad negra de carácter liberador. El ideal panafricano de Marcus Garvey daba valor al sujeto colectivo «Pueblos negros del mundo»; la poesía del movimiento Negro Renaissance de Harlem explicaba las potencialidades expresivas y la sensibilidad del «Nuevo Negro» norteamericano; los versos renovadores del joven Nicolás Guillén proponían la metáfora del «color cubano» de la población mestiza residente en Cuba; y Gustavo Urrutia, con su periodismo audaz, iba perfilando un sujeto negro nuevo, que -a su modo de ver- debería ser denominado afro-cubano ${ }^{50}$ en un sentido amplio de la palabra. En suma, a pesar de sus diferencias ideológicas, cada uno de esos pensadores coadyuvaron a la historia de las ideas contra el racismo anti-negro en América.

\title{
O DEBATE ENTRE INTELECTUAIS AFRO- DESCENDENTES DE AMÉRICA: A PERSPECTIVA CULTURAL COMO BASE DA CONSTRUÇÃO DE UMA SUBJETIVIDADE DE CARÁTER LIBERTÁRIO (1920-1940)
}

\begin{abstract}
RESUMO
Neste ensaio analisarei quatro experiências intelectuais baseadas na cultura, cujo objetivo foi gerar autoestima na população negra de América. O ideal pan-africano de Marcus Garvey, a poesia do movimento Negro Renaissance de Harlem, os versos renovadores de Nicolás Guillén e o jornalismo incisivo de Gustavo Urrutia contribuíram a construir uma subjetividade negra de caráter libertário.
\end{abstract}

50 Término presentado por Fernando Ortiz en sus libros a principios del siglo XX: Hampa afrocubana. Los negros brujos (apuntes para un estudio de etnología criminal) [1906] y Hampa afro-cubana. Los negros esclavos. Estudio sociológico y de derecho público (1916). Ver FERNÁNDEZ-ROBAINA, Tomás. "El término 'afrocubano': Una contribución olvidada de Fernando Ortiz". Identidad Afrocubana, cultura y nacionalidad. Santiago de Cuba: Editorial Oriente, 2009. p. 73-84. 
PALAVRAS-CHAVE: intelectuais negros, movimentos culturais, século XX.

Recebido em: 19/03/12

Aprovado em: 25/11/12 